\title{
Molecular cytogenetics: Show me the colors
}

In this issue of Genetics in Medicine, an article by Jalal and Law entitled: "The Utility of M-FISH in Clinical Cytogenetics" is presented.' The authors examine the utilization of multicolor FISH (M-FISH) in clinical cytogenetics by studying seven cases, six of which were cytogenetically abnormal, to determine the efficacy and utility of this technology. They have shown that this multi-color technology is useful for the identification of marker chromosomes, derivative chromosomes, and in the analysis of complex karyotypes. In addition, they illustrate limitations of this technology and its inability to detect some specific abnormalities. They also compare its limitation to the similar technology of spectral karyotyping (SKY). This article follows a similar article in the inaugural issue of Genetics in Medicine (Volume 1) in which Levy and her colleagues described the utilization of comparative genomic hybridization ( $\mathrm{CGH}$ ) to study 12 abnormal derivative chromosomes (five markers, five unbalanced translocations, and two intrachromosomal duplications), highlighting the utility of this technology also to identify unknown chromosomal material. ${ }^{2}$

The study of chromosomes has a relatively short history, and since Tjio and Levan first identified the correct chromosome number of 46 in humans in 1956, there has been constant improvement and refinement of the technologies that are routinely used for chromosome identification. Analysis of chromosomes using solid staining progressed to identification by banding in 1971, which was followed shortly thereafter (1976) by utilization of high-resolution technology. At that point, advances in cytogenetics came to a standstill and questions concerning the overall efficacy of cytogenetics and its usefulness in the future began to be posed. However, the future applicability of cytogenetics became clearly delineated and apparent with the ground breaking experiments of Pinkel and Gray and of Ward and his colleagues who laid the groundwork in 1988 for molecular cytogenetics, with technology revolving around the utilization of fluorescence in situ hybridization. ${ }^{3-5}$

Today, cytogeneticists have an arsenal of technologies that can be used both clinically and from a research perspective to better understand chromosome structure and function. These techniques can be used to make chromosome identification, to study the mechanism of chromosomal aberrations, and to better understand the phenotypic effects of chromosomal abnormalities. These technologies run the gamut from using single chromosome painting probes to identify one specific chromosome to using single copy probes to look for specific deletions or duplications of material. Comparative genomic hybridization can be utilized to better analyze neoplasia and, as discussed in the article by Jalal and Law presented in this issue of the journal, multicolor FISH or SKY can be used to analyze marker chromosomes, derivative chromosomes, and complex karyotypes. ${ }^{2,6-9}$ All of these technologies have made the field of cytogenetics a much more vibrant and fruitful endeavor, allowing us to unequivocally identify marker chromosomes that are found both prenatally and postnatally. It has allowed distinct phenotypic correlations to be made for many specific markers, specifically those derived from chromosomes 12, 15, 18, and 22. For example, a marker derived from chromosome 15 containing SNRPN will most likely have an abnormal phenotype, whereas the marker without SNRPN will more likely have a normal phenotype. ${ }^{10-14}$ FISH can be used to determine the origin of extra unidentified material on derivative chromosomes and single copy probes can determine the extent of rearrangement. ${ }^{15}$ Both subtle and complex rearrangements can be elucidated by a variety of methods. Using a series of YACs, we have delineated subtle deletions in several cytogenetically "balanced" translocations and have elucidated known genes that are either deleted or present in individuals with cytogenetic deletions. ${ }^{16-17}$ One of the more common uses of FISH, and by many accounts one of the important aspects, is in the identification of microdeletion syndromes. These studies have taught us that the frequency of many abnormalities may be greater than we initially imagined. For example, the frequency of deletions of chromosome 22 may be as high as 1:3000. The National Institutes of Health initiative to create a FISH-BAC map, with markers one megabase apart on every chromosome, provides the opportunity to precisely define structural rearrangements. ${ }^{18}$ We will be able to determine the precise amount of material on accessory marker chromosomes and to identify small deletions in apparently balanced translocations. We have already shown this phenomenon utilizing YACs, but it will be more efficacious with BACs.

With the identification of unique subtelomeric regions on each individual chromosome arm, studies can be done answering whether, and if so to what extent, subtelomeric variation is clinically important. Both cryptic rearrangements as well as cryptic subtelomeric deletions have been associated with idiopathic mental retardation. ${ }^{19,20}$ As the technology increases, it is extremely likely that multicolor telomeric probes will be available in which all of the chromosome arms can be routinely analyzed in appropriate cases.

Interphase analyses have become much more routinely utilized for the rapid prenatal detection of aneuploidy or for the detection of a Bcr-Abl fusion in chronic myelogenous leukemia. A large number of prenatal laboratories are currently doing prenatal interphase analysis, to a limited degree, to rule out aneuploidy of chromosomes $13,18,21, \mathrm{X}$, and $\mathrm{Y}^{21}$ Its applications in cancer cytogenetics have vastly multiplied, in which probes for several different site-specific translocations have been developed. These probes, such as those developed for detecting the Bcr-abl rearrangement in CML, can not only be 
effectively used for studying interphase cells, but have become extremely important for monitoring the effectiveness of treatments. ${ }^{22}$ The utilization of molecular cytogenetics has vastly expanded not only in the clinical realm but also in the research area. Here, this technology has become much more routinely used to better understand meiosis, cell, and nucleus architecture, and in the identification of mouse chromosomes, especially in the creation of embryonic stem cells.

The newest FISH technologies are the multi-color karyotyping techniques as described by Jalal and Law in this issue. ${ }^{1}$ Three major different types of multi-color FISH are available: M-FISH, SKY, and Rx-FISH. M-FISH was first described by Spiecher et al. in 1996. ${ }^{23}$ This technique is based on a combinatorial labeling approach in which six different fluorochromes are utilized in combination, yielding a possible 63 combinations $\left(2^{n}-1\right)$. Using these fluorochromes with optical filters between 350 and $770 \mathrm{~nm}$, they visualized 27 combinatorially labeled probes simultaneously. These were analyzed using sophisticated software allowing each individual chromosome to be pseudocolored. In the same year, Schrock et al. ${ }^{24}$ reported multi-color karyotyping that was interferometer-based spectral imaging, in contrast to the fluorochrome based system described above. They used an interferometer to generate a fluorochrome-specific optical path difference that provides spectral information. In conjunction with a CCD camera, the fluorescence emission spectrum can be recovered simultaneously at all points. Muller et al., in 1997, proposed using crossspecies multi-color banding (Rx-FISH), ${ }^{25,26}$ utilizing probes from flow-sorted gibbon chromosomes. Combinatorial labeling was used and a unique pattern of karyotypic banding involving different colors on each chromosome was generated. Other offshoots of this technology include a multi-color chromosome bar code and high resolution multi-color banding, both of which allow the differentiation of the chromosome at specific regions. ${ }^{27,28}$ As described above, all of these methods can be utilized for a variety of studies. This includes clinical cytogenetics (e.g., the determination of markers and de novo duplications), cytogenetics of neoplasia, radiation biology, cellular architecture, and comparative cytogenetics.

What is truly remarkable is not the advancement of molecular cytogenetic technology but its acceptance and absorbance into the clinical cytogenetics laboratories. These techniques have become much more routinely utilized to expand each laboratory's capability to make proper diagnoses. The vast majority of laboratories in the United States currently have some type of computerized FISH analysis system. More than 70 laboratories already have a spectral karyotyping system. The big question for clinical cytogenetics does not involve how the new technology should be used but what technology is necessary to use. It must also be decided when to use it, how to make it cost effective, and how to have the proper labor effectiveness when performing the technique. As in all fields, technology does not come cheaply. It becomes incumbent upon every laboratory to be able to integrate the technology and maximize its utilization, while still running a well-organized and fiscally responsive laboratory.
In all respects, the future continues to remain bright for molecular cytogenetics. Techniques continue to be tested and to ultimately find their proper place in the clinical laboratory. As work continues, we will see the future development of multi-color telomere probes, a $1 \mathrm{Mb}$ BAC map for all chromosomes, and comparative genomic hybridization with an array technology that might allow for the rapid detection of both deletions and duplications within the genome. These developments should ultimately provide the opportunity to clearly delineate all abnormalities on the molecular level. This will provide detailed phenotype-karyotype for detecting abnormalities, allowing both prenatal and postnatal prognosis of these chromosomal aberrations. All of these technologies are continually being tested and absorbed within the clinical laboratories, which ultimately must determine the best way to diagnose patients and to determine how this technology can best be successful.

Stuart Schwartz, PhD

Department of Genetics and Center for Human Genetics University Hospitals of Cleveland

Cleveland, Ohio

\section{References}

1. Jalal SM, Law, ME. Litility of M-Fish in clinical cytogenetics. Genetics in Medicine 1999;1:181-186

2. Levy B, Dunn TM, Kaffe S, Kardon N, Hirschorn K. Clinical applications of comparative genomic hybridization. Genetics in Medicine 1998:1:4-12

3. Pinkel D, Landegent I, Collins C, Fuscoe I, Segraves R. Lucas I. Gray JW. Fluorescence in situ hybridization with human chromosome specific libraries: Detection of trisomy 21 and translocation of chromosome 4. Proc Natl Acat Sci LSA 1988:85:9138-9142.

4. Cremer T, Lichter P, Borden I, Ward DC. Manuelidis L. Detection of chromosome aberrations in metaphase and interphase tumor cells by in situ hybridization using chromosone specific library probes. Hum Genct 1988:80:235-246.

5. Lichter P, Cremer T, Borden I, Manuelidis L, Ward DC. Delineation of individual human chromosomes in metaphase and interphase cells by in situ suppression hybridization using chromosome specific library probes. Hum Genet 1988:80:224-234.

6. Haddad BR, Schrock E, Meck I, Cowan I, Young H. Ferguson-Smith MA, du Manoir $S$, Ried $T$. Identification of de nowo chromosomal markers and derivatives by spectral karyotyping. Hum Genet 1998;103:619-625.

7. Huang B, Ning Y, L.amb AN, Sandlin CI, Jamehdor N.I, Ried T, Bartley J. Identification of an unusual marker chromosome by spectral karyotyping. Am I Med Gonet $1998: 80: 368-372$

8. Phelan MC, Bluckburn W, Rogers RC, Crawford EC, Cooley NR Ir. Schrock E, Ning $Y$. Ried T. FISH analysis of a complex chromosome rearrangement involving nine breakpoints on chromosomes 6, 12,14 and 16. Prenat Diagn 1998:18:1174-1180.

9. Schrock E, Veldman T, Padilla-Nash H, Ning Y, Spurbeck J, Jalal S, Shaffer LG, Papenhausen P. Kozma C, Phelan MC, Kjeldsen E, Schonberg SA, O'Brien P. Biesecker $L$, du Manoir S, Ried T. Spectral karyotyping refines cytogenetic diagnostics of constitutional chromosomal abnormalities. Hum Genet 1997;101:255-262.

10. Crolla IA. FISH and molecular studies of autosomal supernumerary marker chromosomes excluding those derived from chromosome 15. 11. Review of Literature. Am I Med Ginet 1998;75:367-381.

11. Crolla JA, Long F, Rivera H, Dennis NR. FISH and molecular study of autosomal supernumerary marker chromosomes excluding those derived from chromosome 15 and 22. 1. Results of 26 new cases. Am J Med Genct 1998:75:355-366.

12. Schwartz S. Depinet TW, Leana-Cox I, Isada NB, Karson EM, Park VM, Pasztor LM, Sheppard LC, Stallard R, Wolff DI, Zinn AB, Zurcher VL, Zackowski IL. Sex chromosome markers: Characterization using fluorescence in situ hybridization and review of literature. Am J Med Genct 1997:71:1-7

13. Vierbach R, Engels H, Gamerdinger U, Hansmann M. Delineation of supernumerary marker chromosomes in 38 patients. Am J Met Gint 1998;76:351-358.

14. Lena-Cox I, lenkins L, Palmer CG, Plattner R, Sheppard L. Flejter WL, Zackowski J, Tsien F. Schwartz S. Molecular cytogenetic analysis of inv dup (15) chromosomes, using probes specific for the Prader-Willi/Angelman syndrome region: Clinical implications. Am J Hum Genct 1994;54:748-756. 
15. Lena-Cox J. Levin S, Surana R, Wulfsherg E, Keene CL, Raffel LJ, Sullivan B, Schwartz S. Characterization of de novo duplications in eight patients by using fluorescence in situ hybridization with chromosome-specific DNA libraries. Am / Hum Ge'net 1993;52:1067-1073.

16. Kumar A, Becker LA, Depinet TW, Haren IM, Kurtz CL, Robin NH, Cassidy $S B$, Wolff DI, Schwartz S. Molecular characterization and delineation of subtle deletions in de novo "balanced" chromosomal rearrangements. Hum Genet 1998;103:173-178.

17. Sirko-Osadsa A, Cassidy SB, Depinet TW, Robin NH, Limwongse C, Schwartz S. Molecular refinement of karyotype: Beyond the cytogenetic band. Genetics in Medicine 1999;6: In press.

18. National Cancer lnstitutes. A resource of arrayed BAC clones for identification of cancer chromosome aberrations. http://bacpac.med.buffalo.edu/human/overview.html

19. Knight SJ, Horsley SW, Regan R, Lawric NM, Maher EJ, Cardy DL, Flint J, Kearney L. Development and clinical application of an innovative fluorescence in situ hybridization technique which detects submicroscopic rearrangements involving telomeres. Eur J Hum Genet 1997:5:1-8

20. Flint I, Wilkie AO, Buckle VI, Winter RM, Holland AJ, McDermid HE. The detection of subtelomeric chromosomal rearrangements in idiopathic mental retardation. Nat G'ne't 1995:9:132-140.

21. Ward BE, Gersen SL, Carelli MP, McGuire NM, Dackowski WR, Weinstein M, Sandlin $\mathrm{C}$, Warren $\mathrm{R}$, Klinger $\mathrm{KW}$. Rapid prenatal diagnosis of chromosomal aneuploidies by fluorescence in situ hybridization: Clinical experience with 4500 specimens.
Am J Hum Genet 1993;52:854-865.

22. Deward GW, Wyatt WA, Juneau AL, Carlson RO, Zinsmeister AR, Jalal SM, Spurbeck JL, Silver RT. Highly sensitive fluorescence in situ hybridization method to detect double BCR/ABL fusion and monitor response to therapy in chronic myeloid leukemia. Blood 1998;91:3357-3365.

23. Speicher MR, Ballard SG, Ward DC. Karyotyping human chromosomes by combinatorial multi-fluor FISH. Nat Genet 1996:12:368-375.

24. Schrock E, du Manoir S, Veldman T, Schoell B, Wienberg J, Ferguson-Smith MA, Ning Y, Ledbetter DH, Bar-Am I, Soenksen D, Garini Y, Ried T. Multicolor spectral karyotyping of human chromosomes. Science 1996;273:494-497.

25. Muller S, O'Brien PC, Ferguson-Smith MA, Wienberg J. A novel source of highly specific chromosome painting probes for human karyotype analysis derived from primate homologues. Hum Genet 1997;101:149-153.

26. Muller S, O'Brien PC, Ferguson-Smith MA, Wienberg J. Cross-species colour segmenting: A novel tool in human karyotype analysis. Cytometry 1998;33: $445-452$.

27. Muller S, Rocchi M, Ferguson-Smith MA, Wienberg J. Toward a multicolor chromosome bar code for the entire human karyotype by fluorescence in situ hybridization. Hum Genet 1997;100:271-278.

28. Chudoba I, Plesch A, Lorch T, Lemke I, Claussen U, Senger G. High resolution multicolor-banding: A new technique for refined FISH analysis of human chromosomes. Cytogenet Cell Genet 1999;84:156-160.

\section{Coming in Genetics in Medicine September/October 1999 Issue}

\section{Original Articles}

Population-based studies reveal differences in the allelic frequencies of two functionally significant human interleukin-4 receptor polymorphisms in several ethnic groups

Caggana M, Walker K, Reilly AA, Conroy JM, Duva S, Walsh AC

Molecular refinement of karyotype: Beyond the cytogenetic band Sirko-Osadsa DA, Cassidy SB, Depinet TW, Robin NH, Limwongse C, Schwartz S

Inconsistencies in genetic counseling and screening for consanguineous couples and their offspring:

The need for practice guidelines

Bennett RL, Hudgins L, Smith CO, Motulsky AG

Exon $10 \mathrm{~b}$ of $\mathrm{NF} 1$ gene represents a mutatinal hotspot and harbors a recurrent missense mutation Y489C associated with aberrant splicing

Messiaen LM, Callens T, Roux KJ, Mortier GR, DePaepe A, Abramowicz M, Pericak-Vance MA, Vance $J M$, Wallace $M R$

Transmission of Angelman Syndrome by an affected mother Lossie AC, Driscoll DJ

\section{Brief Report}

Medium-chain acyl-CoA dehydrogenases deficiency: Sudden and unexpected death of a 45 year old woman

Raymond $K$, Bale AE, Barnes $C A$, Rinaldo $P$

\section{Invited Review/CME Article}

Hearing loss

Rehm H 